\title{
THE EFFECTS OF ASPIRIN AND METHYSERGIDE, SINGLY AND IN COMBINATION, ON SYSTEMIC HAEMODYNAMIC RESPONSES TO PULMONARY EMBOLISM*
}

\author{
Martin H. Todd, James B. Forrest and David B.J. Cragg
}

\begin{abstract}
Agstract
Pretreatment of anaesthetized rabbits with aspirin (A), $250 \mathrm{mg} \cdot \mathrm{kg}^{-1}$, methysergide $(\mathrm{M})$ $3 \mathrm{mg} \cdot \mathrm{kg}^{-1}$ or a combination of both $(\mathrm{A}+\mathrm{M})$ was done before pulmonary embolism with a $1.0 \mathrm{ml}$ autologous blood clot and compared with no pretreatment (C). Experiments were done until 10 survivors were present in each group. Mortality rate in controls $(C)$ was 55 per cent (death in less than 30 minutes) compared to zero in (A) and $(A+M)$ and nine per cent in (M). Arterial blood pressure fell to 60 per cent of pre-embolism values two minutes after embolism in (C) but had returned to 85 per cent of pre-embolism values after 60 minutes. This compares with a drop to 82 per cent at two minutes and 83 per cent at 60 minutes in (A), a drop to 70 per cent at two minutes and 90 per cent at 60 minutes in (M) and a very small drop to 92 per cent at two minutes which was unchanged at 60 minutes in $(A+M)$. Right ventricular pressure increased by 75 per cent after two minutes compared to pre-embolism values in $(C)$ and was still elevated by 37 per cent after 60 minutes. This compares with increases at two minutes and 60 minutes respectively of 58 and 23 per cent in (A), 65 and 35 per cent in (M) and 55 and 18 per cent in $(A+M)$. Heart rate did not show any significant changes in any of the groups after embolism.

These results show a dramatic reduction in mortality from pulmonary embolism with aspirin or methysergide pretreatment, which is associated with significant attenuation of the hypotensive response seen in controls. These agents may act by inhibiting the actions of a release of prostaglandins and serotonin. The additive effects of the combination used suggests that both mediators may play a role in the haemodynamic responses to pulmonary embolism.
\end{abstract}

Key Words: Pharmacology, Aspirin, Methysergide, haemodynamic effects; EмBoLISM, pulmonary.

Pulmonary Embolism contributes to 20 per cent of hospital deaths ${ }^{1}$ and 66 per cent of patients who suffer a massive pulmonary embolism die within the first hour. ${ }^{2}$ If the blockage of the pulmonary vasculature is sudden and extensive, death may quickly follow due to the inability of the right ventricle to maintain cardiac output. ${ }^{3}$ Acute systemic hypotension results, and death has been attributed to reduced coronary flow ${ }^{4}$ or failure of the respiratory centre due to an insufficient blood supply. ${ }^{5}$ The aim of immediate therapy following severe pulmonary embolis $m$ is

Martin H. Todd, Ph.D., Ontario Heart Foundation Research Fellow, Department of Medicine; James B. Forrest, M.B., Ch.B., Ph.D., F.F.A.R.C.S., Professor and Chairman, Department of Anaesthesia; David B.J. Cragg, Research Laboratory Coordinator, Department of Anaesthesia; McMaster University, Hamilton, Ontario.

Address for Correspondence: Dr. J.B. Forrest, Professor \& Chairman, Department of Anaesthesia, McMaster University, Box 2000, Station A, Hamilton, Ontario, Canada L8N 3Z5.

* Supported by Ontario Heart Foundation Grant \#15-19 and Medical Research Council of Canada Grant \#MA 5811.

Canad. Anaesth. Soc. J., vol. 28, no. 4, July 1981 to stabilize the cardiorespiratory system, improve left ventricular filling and increase pulmonary blood flow. ${ }^{6}$ Several factors may contribute to the reduced pulmonary blood flow: mechanical obstruction by the embolus, local release of humoral pulmonary vasoconstrictor substances and reflex vasoconstriction. Some workers have attributed the pulmonary vascular effects solely to mechanical obstruction by the embolus. ${ }^{1,7,8}$ Others have commented on the discrepancy between the degree of obstruction and the resulting haemodynamic outcome, both in $\operatorname{man}^{9}$ and in experimental animals. ${ }^{10}$ These observations may be accounted for in part by pulmonary vasoconstriction resulting from the release of humoral mediators.

Humoral substances which may be responsible for the pulmonary vasoconstriction include prostaglandins, histamine and serotonin. ${ }^{11-13}$ Inhibitors of the synthesis of prostaglandins have been shown to decrease the pulmonary vascular pressor response following embolization with a small blood clot introduced into a lobar pulmonary artery. ${ }^{14}$ In addition, pretreatment of animals with high doses of aspirin reduced the mortality 
following massive pulmonary embolism. is The role of histamine is not clear since experiments using mepyramine have yielded conflicting results $^{13}$ and injected histamine does not invoke pulmonary hypertension. ${ }^{16}$ Serotonin, however, appears to be released following embolization since a reduction in the synthesis or release of serotonin is accompanied by smaller pulmonary haemodynamic changes and induced mortality. ${ }^{17.18}$ Several factors including mechanical obstruction, prostaglandins and serotonin appear to be implicated in the responses produced following pulmonary embolism, but the relative contributions or site of action of the humoral mediators is not clear. Experiments in which animals have been pretreated with single antagonists suggest that a considerable proportion of the response due to embolization results from mechanical obstruction of the pulmonary vasculature. Pretreatment of animals with a combination of a prostaglandin synthesis inhibitor and an antagonist of serotonin, however, almost completely abolishes the pulmonary pressor response produced by a relatively small embolus. ${ }^{14}$ If similar effects were produced following massive pulmonary embolism a combination of these two antagonists would be more effective than each agent administered singly in reducing the systematic haemodynamic changes.

These experiments were designed, therefore, to investigate the effects of aspirin and methysergide, given singly and in combination, on the haemodynamic responses and on mortality resulting from severe pulmonary embolism.

\section{METHODS}

Male New Zealand white rabbits weighing 2.6 to $3.2 \mathrm{~kg}$ were anaesthetized with intravenous sodium pentobarbitone. The treachea was cannulated and animals breathed spontaneously. Polyethylene cannulas, PE205, were inserted into the aortic arch through the right common carotid artery and into the right ventricle through the right external jugular vein. Aortic and right ventricular blood pressures were measured with Statham P23dB transducers and, together with heart rate which was derived electronically from lead II of the electrocardiogram, were displayed on a Hewlett-Packard recorder. A stabilization period of $30 \mathrm{~min}$ was allowed before measurements were made. Aortic blood pressure, right ventricular pressure and heart rate were measured $30 \mathrm{sec}$ before and $1,2,5,10,30$, and $60 \mathrm{~min}$ following embolization with $1.0 \mathrm{ml}$ of blood clot injected into the lungs through the right ventricular catheter. The blood clot was prepared $20 \mathrm{~min}$ before embolization by removing $1.0 \mathrm{ml}$ of blood from a donor rabbit, adding 1.0 unit of thrombin and injecting this clotting blood into a siliconized polyethylene tube $P E 280,22 \mathrm{~cm}$ long. This retracted blood clot was injected into the lungs through the right ventricular catheter 20 minutes later.

Rabbits were divided into four pre-treatment groups. Saline, aspirin $250 \mathrm{mg} \cdot \mathrm{kg}^{-1}$, methysergide $3 \mathrm{mg} \cdot \mathrm{kg}^{-1}$, and a combination of aspirin $250 \mathrm{mg} \cdot \mathrm{kg}^{-1}$ and methysergide $3 \mathrm{mg} \cdot \mathrm{kg}^{-1}$. These drugs were administered intravenously $20 \mathrm{~min}$ before embolization. Animals were assigned randomly to the pretreatment groups. Responses for each haemodynamic variable within each group were compared with the preembolism value or pretreatment values by Student paired t-test. Equivalent pre-embolism and post-embolism values between groups were compared by the Mann-Whitney U-test. Sufficient animals were used from each pretreatment group so that there were 10 survivors in each group.

At the end of the experiment the animals were killed and the heart and lungs were removed. The main pulmonary artery and its branches to each lobe of the lung were carefully dissected out and the position of the clot was recorded.

\section{RESULTS}

Embolization of control animals with $1.0 \mathrm{ml}$ of autologous clot resulted in a mortality rate of 55 per cent. There were appreciable differences in the haemodynamic responses of survivors and non-survivors, therefore the results from these two groups have been analyzed separately.

In the survivors $(\mathrm{n}=10)$ embolization produced immediate increase in right ventricular pressure, an increase in heart rate and a decrease in aortic pressure (Figure 1). Systolic and diastolic right ventricular pressure increased by 1.86 $\pm 0.8 \mathrm{kPa}(14 \pm 6 \mathrm{~mm} \mathrm{Hg}$ ) and $0.67 \pm 0.266 \mathrm{kPa}(5$ $\pm 2 \mathrm{~mm} \mathrm{Hg}$ ) respectively. At the same time aortic systolic pressure fell by $4.92 \pm 2.53 \mathrm{kPa}$ (37 \pm $19 \mathrm{~mm} \mathrm{Hg})$ and $5.05 \pm 2.39 \mathrm{kPa}(39 \pm 18 \mathrm{~mm} \mathrm{Hg})$ respectively. Heart rate increased significantly ( $p$ $<0.05$ ) by $10 \pm 12$ beats per min one minute after embolization but returned to control values within two minutes. In contrast the increase in right ventricular pressure and the drop in aortic pressure were longer lasting and $60 \mathrm{~min}$ following embolization had not returned to pre-embolization values (Figure 1). 

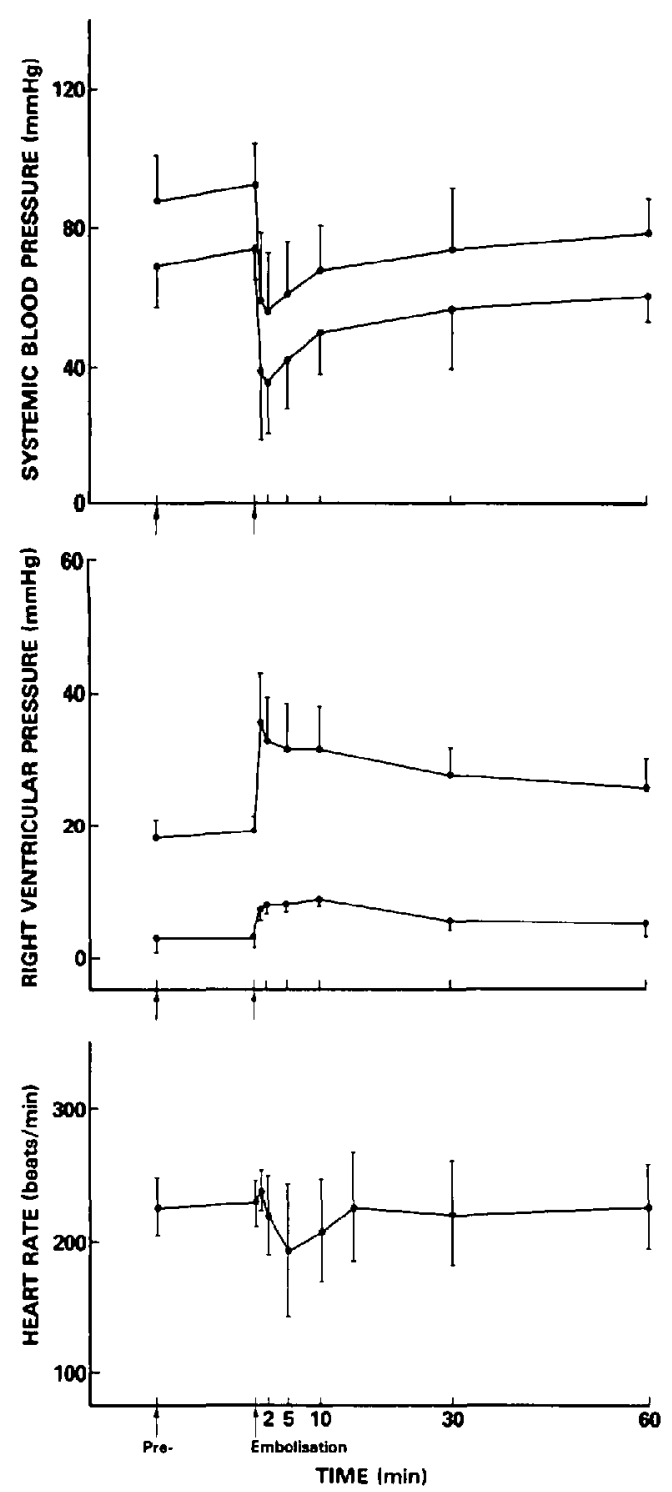

FIgURE I Mean value ( $\pm 1 \mathrm{SD}$ ) of systemic blood pressure, right ventricular pressure and heart rate induced by pulmonary embolization in the ten surviving control animals. Data from the 12 non-surviving animals (Figure 2) were excluded from all comparisons between control and pretreatment groups.

There were 12 non-survivors in the control group and of these, 11 died within five minutes of embolization; however one animal survived until 30 minutes following embolization. Right ventricular pressure and aortic pressure changes were qualitatively similar to those observed in the control group. However the heart rate did not increase following embolization but dropped, so that two minutes after embolization there was a significant $(\mathrm{p}<0.001)$ decrease in heart rate by 44 \pm 23 beats per min. Immediately after embolization there were no significant differences between survivors and non-survivors so that at $30 \mathrm{sec}$ systolic right ventricular and aortic pressures were $5.19 \pm 0.53 \mathrm{kPa}(39 \pm 4 \mathrm{~mm} \mathrm{Hg})$ and $5.45 \pm$ $1.46 \mathrm{kPa}(41 \pm 11 \mathrm{~mm} \mathrm{Hg}$ ) in non-survivors, compared with $4.12 \pm 1.06 \mathrm{kPa}(31 \pm 8 \mathrm{~mm} \mathrm{Hg})$ and $7.85 \pm 2.66 \mathrm{kPa}(59 \pm 20 \mathrm{~mm} \mathrm{Hg})$ in survivors Two minutes later, however, quantitative differences were apparent as systemic blood pressure in the non-survivors fell (Figure 2).

Pretreatment of animals with aspirin 250 $\mathrm{mg} \cdot \mathrm{kg}^{-1}$, increased right ventricular and aortic pressure but did not affect heart rate. Right ventricular systolic and diastolic pressure increased significantly $(\mathrm{p}<0.005)$ by $0.53 \pm$ $0.226 \mathrm{kPa}(4 \pm 2 \mathrm{~mm} \mathrm{Hg})$ and $0.266 \pm 0.133 \mathrm{kPa}(2$ $\pm 1 \mathrm{~mm} \mathrm{Hg}$ ) respectively and aortic, systolic and diastolic pressures by $1.46 \pm 0.8 \mathrm{kPa}(11 \pm 6 \mathrm{~mm}$ $\mathrm{Hg})$ and $1.6 \pm 0.93 \mathrm{kPa}(12 \pm 7 \mathrm{~mm} \mathrm{Hg})$. These responses were relatively transient and were not present $20 \mathrm{~min}$ later. Embolization resulted in increased right ventricular pressure and decreased aortic pressure but none of these animals died (Figure 3). Following embolization right ventricular systolic and diastolic pressures increased by $1.73 \pm 0.8 \mathrm{kPa}(13 \pm 6 \mathrm{~mm} \mathrm{Hg})$ and $0.53 \pm 0.266 \mathrm{kPa}(4 \pm 2 \mathrm{~mm} \mathrm{Hg})$ respectively two minutes following embolization and aortic, systolic and diastolic pressures fell by $2.53 \pm 2.0 \mathrm{kPa}$ $(19 \pm 15 \mathrm{~mm} \mathrm{Hg})$ and $2.93 \pm 2.39 \mathrm{kPa}(22 \pm 18 \mathrm{~mm}$ $\mathrm{Hg}$ ) respectively. There was a significant decrease in the magnitude of the aortic pressure ( $p$ $<0.001)$ and heart rate $(\mathrm{p}<0.001)$ responses following embolization between control animals and animals which had been pretreated with aspirin. However, 60 min after embolization the aortic blood pressure was still significantly ( $\mathrm{p}<$ 0.005 ) below pre-embolization values (Figure 3 ). The right ventricular pressure changes were not significantly different from those observed in control animals.

Administration of methysergide $3 \mathrm{mg} \cdot \mathrm{kg}^{-1}$ resulted in an increase in aortic pressure, a decrease in heart rate, but had no effect on right ventricular pressure. Heart rate and aortic pressure were still affected $20 \mathrm{~min}$ later. Aortic systolic and diastolic pressures were reduced by $0.8 \pm 0.4 \mathrm{kPa}(6 \pm 3 \mathrm{~mm} \mathrm{Hg})$ and $0.8 \pm 0.53 \mathrm{kPa}$ $(6 \pm 4 \mathrm{~mm} \mathrm{Hg}$ ) respectively and heart rate was decreased by $25 \pm 13$ beats per minute. Embolization resulted in increased right ventricular pressure, increased aortic pressure but no significant effect on heart rate (Figure 4) and one 

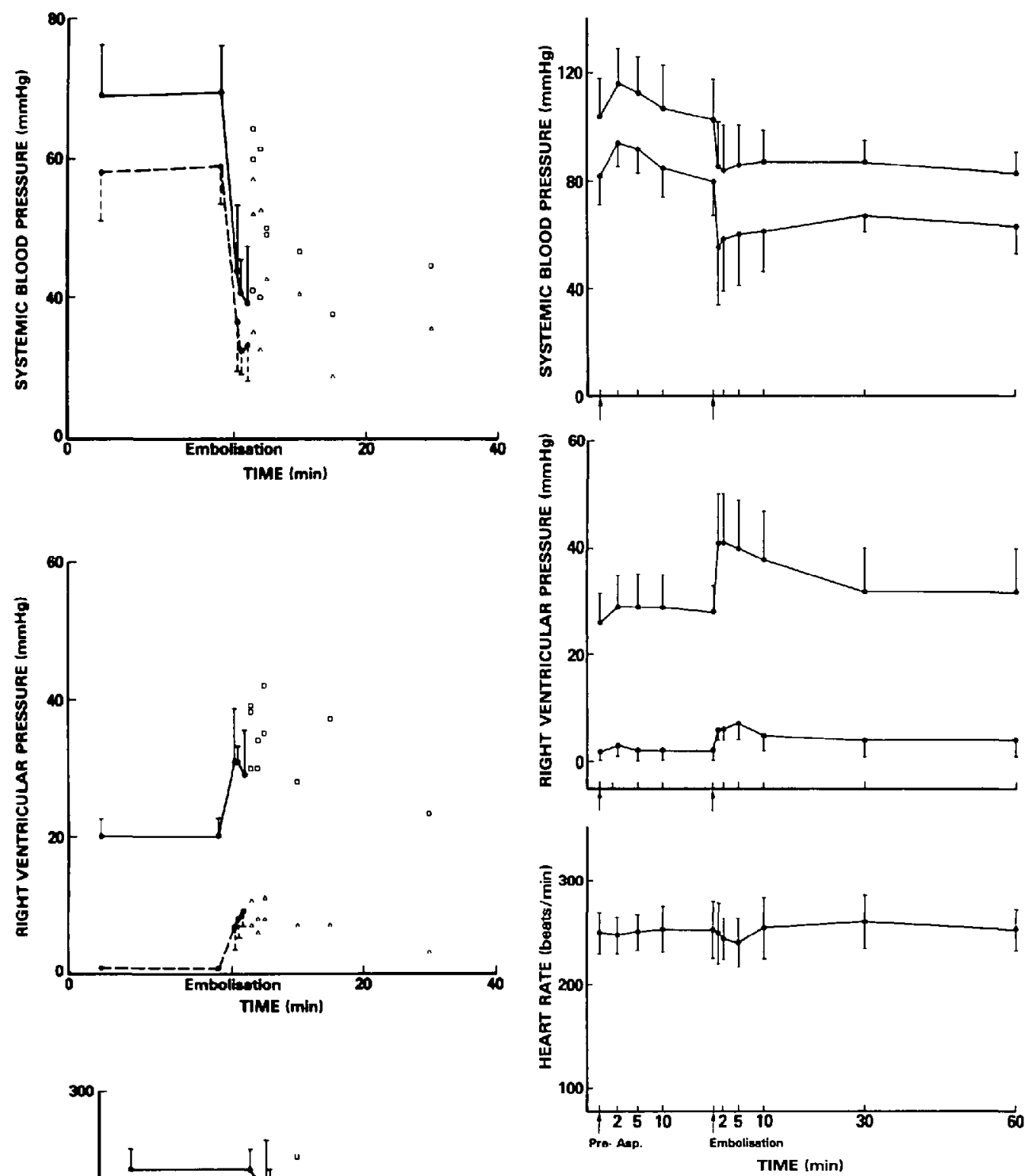

Figure 3 Mean value ( \pm 1 SD) of systemic blood pressure, right ventricular pressure and heart rate induced by pulmonary embolization in ten animals pretreated with aspirin $250 \mathrm{mg} \cdot \mathrm{kg}^{-1}$.

animal died. Following embolization right ventricular systolic and diastolic pressures increased by $1.86 \pm 0.67 \mathrm{kPa}(14 \pm 5 \mathrm{~mm} \mathrm{Hg})$ and $0.53 \pm$ $0.266 \mathrm{kPa}$ ( $4 \pm 2 \mathrm{~mm} \mathrm{Hg}$ ) respectively and aortic systolic and diastolic pressures fell by $2.79 \pm$ $2.39 \mathrm{kPa}(21 \pm 18 \mathrm{~mm} \mathrm{Hg})$ and $2.53 \pm 2.0 \mathrm{kPa}$ (19 $\pm 15 \mathrm{~mm} \mathrm{Hg}$ ). There was no significant difference between the increase in right ventricular pressure induced by embolism in control animals and in those animals pre-treated with methysergide. There was, however, a significant ( $p<0.005$ ) difference in the magnitude of the aortic blood pressure, right ventricular pressure and heart rate induced by pulmonary embolism in the 12 nonsurviving control animals. 

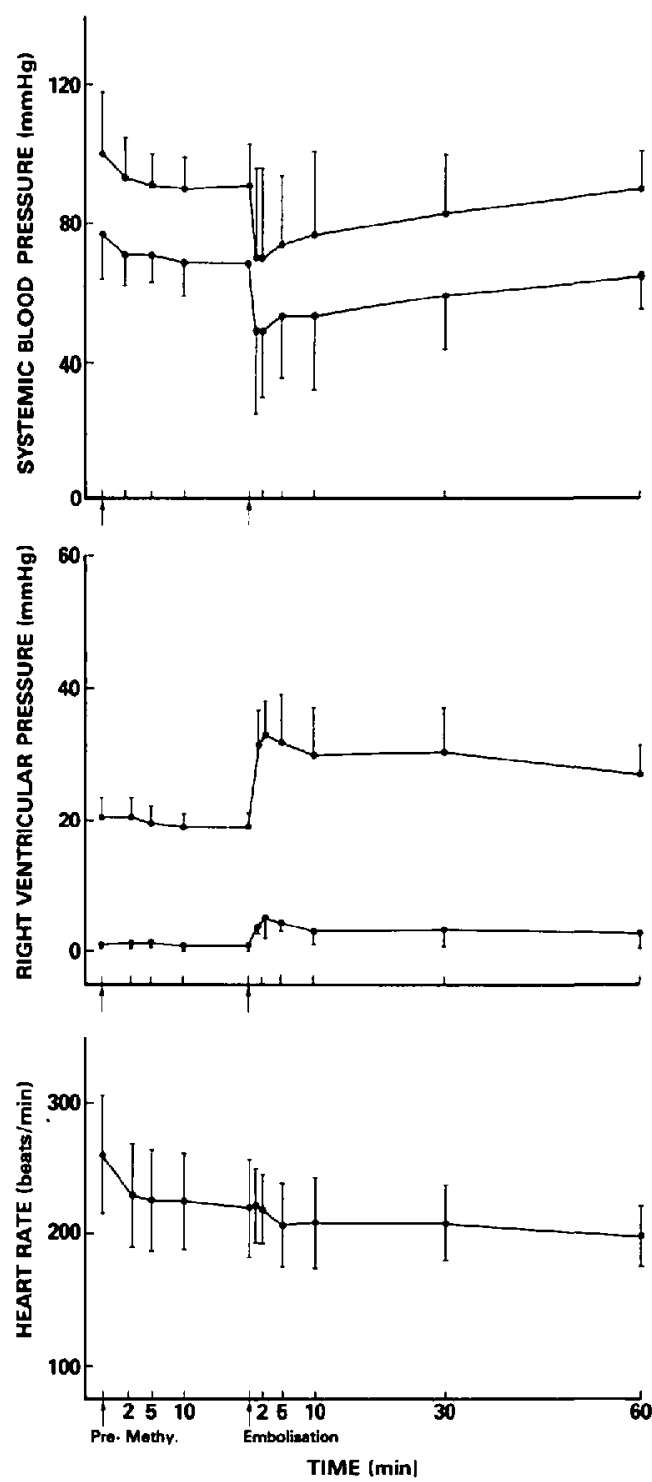

Figure 4 Mean value ( \pm 1 SD) of systemic blood pressure, right ventricular pressure and heart rate induced by pulmonary embolization in ten animals pretreated with methysergide $3 \mathrm{mg} \cdot \mathrm{kg}^{-1}$.

pressure response to embolization between control animals and those which had been pretreated with methysergide. In addition the recovery of aortic blood pressure following embolization was more rapid than in the control or aspirin treated animals so that $60 \mathrm{~min}$ following embolization the systolic aortic pressure was not significantly different from pre-embolization values (Figure 4).

Administration of a combination of aspirin and methysergide increased right ventricular pressure, increased aortic pressure and decreased heart rate. Systolic and diastolic right ventricular pressure increased by $0.56 \pm 0.27 \mathrm{kPa}(4 \pm 2 \mathrm{~mm}$ $\mathrm{Hg})$ and $0.40 \pm 0.133 \mathrm{kPa}(3 \pm 1 \mathrm{~mm} \mathrm{Hg})$ and increased aortic systolic and diastolic pressures by $2.26 \pm 1.73 \mathrm{kPa}(17 \pm 13 \mathrm{~mm} \mathrm{Hg})$ and $1.60 \pm$ $1.20 \mathrm{kPa}(12 \pm 9 \mathrm{~mm} \mathrm{Hg})$ and increased heart rate by $30 \pm 15$ beats per minute. The right ventricular and aortic pressures and heart rate had, however, returned to pre-administration values $20 \mathrm{~min}$ later. Embolization resulted in an increase in right ventricular pressure, a small reduction in aortic pressure and an increase in heart rate and none of the animals died (Figure 5). Following embolization right ventricular systolic and diastolic pressures increased by $1.60 \pm 0.53 \mathrm{kPa}(12 \pm$ $4 \mathrm{~mm} \mathrm{Hg})$ and $0.27 \pm 0.27 \mathrm{kPa}(2 \pm 2 \mathrm{~mm} \mathrm{Hg})$ There was no significant difference between right ventricular pressure responses in control animals and in those animals pretreated with aspirin and methysergide. Heart rate increased by $14 \pm 15$ beats per min, an effect which also occurred in control animals but not in animals pretreated with aspirin or methysergide alone. There was a significant difference in the aortic blood pressure response following embolization between control animals and those animals pretreated with a combination of aspirin and methysergide. In animals pretreated with this combination, the aortic pressure following embolization fell by only 0.80 $\pm 0.80 \mathrm{kPa}(6 \pm 6 \mathrm{~mm} \mathrm{Hg})$ compared with the fall of $4.92 \pm 2.53 \mathrm{kPa}(37 \pm 19 \mathrm{~mm} \mathrm{Hg})$ in surviving control animals and $7.71 \pm 3.19 \mathrm{kPa}(58 \pm 24 \mathrm{~mm}$ $\mathrm{Hg}$ ) in non-survivors.

Aortic pressure which fell following embolization, did not return towards pre-embolisation values and $60 \mathrm{~min}$ following embolization aortic pressure was still significantly $(\mathbf{p}<0.001)$ lower than pre-embolization values.

Examination of the distribution of the embolus post-mortem revealed two major patterns of distribution. The majority of emboli ( 60 per cent) obstructed the right main pulmonary artery and were labelled "saddle" emboli. In the second group the embolus was more fragmented and did not obstruct the main pulmonary artery but obstructed major portions of both the left and right lobar pulmonary arteries. This group was labelled "broken" emboli. The clot position was not related to the increase in right ventricular pressure, the decrease in aortic pressure, or death in control animals or in any of the pretreatment groups.

\section{Discussion}

The responses to pulmonary embolism which 

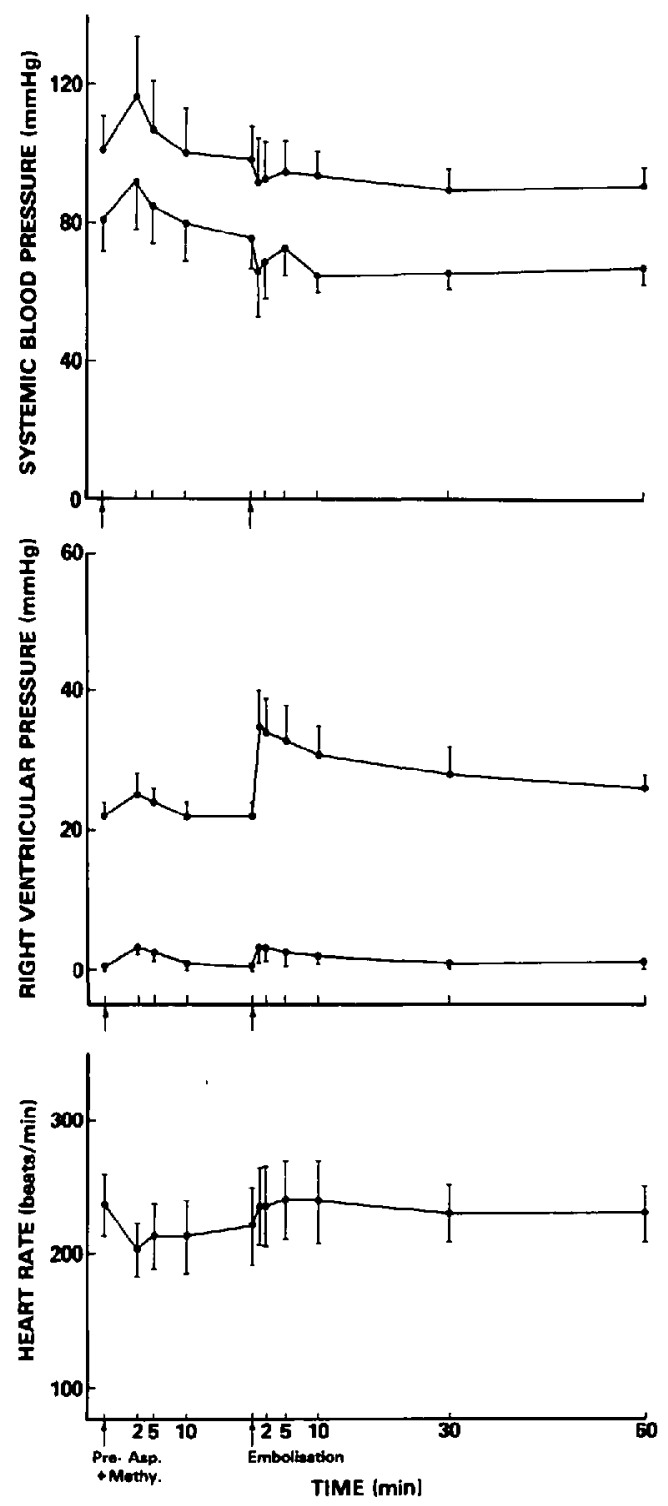

Figure 5 Mean value ( \pm 1 SD) of systemic blood pressure, right ventricular pressure and heart rate induced by pulmonary embolisation in ten animals pretreated with a combination of aspirin $250 \mathrm{mg} \cdot \mathrm{kg}^{-1}$ and methysergide $3 \mathrm{mg} \cdot \mathrm{kg}^{-1}$

were observed in these experiments, increased right ventricular pressure, decreased aortic pressure with little effect on heart rate, are in accord with observations in other species using blood clot emboli. ${ }^{3.19-21}$ These responses have been investigated intensively by others who have shown that the obstruction to blood flow in the pulmonary arterial tree produces an increased right ventricular pressure, reduced cardiac output and systemic hypotension. ${ }^{3.22}$ Consequently these experiments were not designed to analyse the mechanisms involved in the cardiovascular responses to pulmonary embolism, but to investigate whether a combination of agents which have been shown to be effective in reducing the pulmonary pressor responses would alter the systemic hypotensive response following massive embolization.

Pretreatment of animals with aspirin raised systemic and pulmonary arterial pressures, due to an increased force of cardiac contraction. ${ }^{23,24}$ These effects were transient and not present immediately before embolization. Methysergide, however, produced longer lasting direct effects which are due to a serotonin-like effect and which persisted throughout the pretreatment period, altering the pre-embolization values. These effects of methysergide were not evident when aspirin and methysergide were administered in combination. A decrease in the mortality rate in all the pretreatment groups was accompanied by a reduction in the systemic hypotension which followed embolization. This effect was only moderate in the groups treated singly with aspirin or methysergide but extremely striking in the aspirin and methysergide group, in which some animals exhibited no change in systemic blood pressure after embolization. Since only methysergide produced any cardiovascular depression, the reduction in mortality in animals pretreated with aspirin, methysergide or a combination of both, was not due to prior cardiac stimulation. These results suggest that a moderate reduction in systemic hypotension may reflect a significant improvement in vital organ perfusion. The increases of right ventricular pressure were not significantly reduced in any of the pretreatment groups as compared with controls. These results can be explained on the basis that the right ventricular output quickly rises to a maximum if there is massive obstruction of the pulmonary vasculature. ${ }^{3}$ An increase in pulmonary blood flow in these circumstances, due to blockade of vasospasm, need not be reflected in a drop in right ventricular pressure, since it may still be maximally increased.

Although there has been controversy concerning the importance of vasospasm following pulmonary embolism, it is generally accepted that pulmonary vasospasm does occur. ${ }^{1,10}$ The mechanisms responsible for this effect are not clear but they include hypoxia; ${ }^{1}$ hypocapnia; ${ }^{25}$ release of prostaglandins ${ }^{26}$ or serotonin. ${ }^{18}$ The role of any one of these factors or the interplay between them is also not clear, but our experiments 
suggest that agents which interfere with either prostaglandin synthesis or serotonin action have additive effects in reducing the hypotension which occurs following embolism. Although the doses of aspirin used in this study are high compared with those used to block prostaglandin synthesis in the platelet ${ }^{27}$ we have previously demonstrated that doses of aspirin in excess of $100 \mathrm{mg} \cdot \mathrm{kg}^{-1}$ are required to produce a significant decrease in mortality following pulmonary embolism. ${ }^{14}$ This latter study was confined to the measurement of pulmonary vascular responses, but showed that high doses of prostaglandin synthesis inhibitors reduced or abolished the normal pulmonary vascular hypertensive response to pulmonary embolism.

These experiments demonstrate that aspirin and methysergide produce an additive effect and virtually abolish the hypotension and mortality which accompany clot-induced pulmonary embolism. The site of action of these substances may be on the pulmonary artery itself due to antagonism of serotonin and prostaglandin release. Although there is some question as to the role of serotonin in human pulmonary embolism, there is no doubt that prostaglandins produce pulmonary hypotension in man, and a disturbance in the balance of synthesis and metabolism of prostaglandins has already been implicated in some types of pulmonary hypertension. ${ }^{28}$ It is interesting to speculate whether relatively high doses of aspirin within the clinical dose range may produce the kind of beneficial effects observed in this animal model when given over long time periods.

\section{ACKNOWLEDGEMENTS}

The authors would like to thank Carole Chambers for her expert technical assistance, Mona Northey for typing the manuscript, Dr. E.E. Daniel for advice and encouragement, and Dr. G. Murphy (Sandoz) for the methysergide.

\section{REFERENCES}

1. McIntyre, K.M., Sasahara, A.A. \& Shakma, B.V.R.K. Pulmonary thromboembolism. Current Concepts. Adv. Int. Med. 18: 199-218 (1972).

2. Graham, L.W. A study of pulmonary embolism. Arch. Int. Med. 108: 189-207 (1961).

3. Megibow, R.S., KATZ, L.N. \& Steinitz, F.S. Dynamic changes in experimental lung embolism. Surgery $11:$ 19-32 (1942).

4. GRAY, F.D. JR., Pulmonary embolism. Lea and Febiger, Philadelphia, 1966.

5. Marshall, R. Pulmonary embolism. Thomas, Springfield, Illinois, 1965.
6. Alpert, J.S., Francis, G.S., Viewig, W.V.R., Thompson, S.I., Stanton, K.C. \& Hagen, A.D. Pulmonary hypertension secondary to minor pulmonary embolism. Chest 73: 795-797 (1978).

7. DEXTER, L. \& SMITH, G.T. Quantitative studies of pulmonary embolism. Am. J. Med. Sci. 247: 641648 (1964).

8. Parmley, L.F., North, R.L. \& OTt, B.S. Hemodynamic alterations of acute pulmonary thromboembolism. Circ. Res. 11:450-465 (1962).

9. Moser, K.M. Pulmonary embolism. Am. Rev. Respir. Dis. 115: 829-852 (1977).

10. Alpert, J.S., Godtfredsen, J., OCkene, I.S., ANAS, J. \& Dalen, J.E. Pulmonary hypertension secondary to minor pulmonary embolism. Chest 73: 795-797 (1978).

11. Parratt, J.R. \& Sturgess, R.M. The possible roles of histamine, 5-hydroxytryptamine and prostaglandin $\mathrm{F}_{2 \alpha}$ as mediators of the acute pulmonary effects of endotoxin. Br. J. Pharmacol. 60: 209-219 (1977).

12. Radegran, K. Circulatory and respiratory effects of induced platelet aggregation. An experimental study in dogs. Acta Chir. Scand. Supp. 420: 4-24 (1971).

13. Tucker, A.. Weir, E.K., Reeves, J.T. \& Grover, R.F. Pulmonary microembolism: attenuated pulmonary vasoconstriction with prostaglandin inhibitors and antihistamines. Prostaglandins $1 /: 31-41$ (1976).

14. Todd, M.H., Crago, D.J. \& Forrest, J.B. The effects of aspirin and methysergide on responses to clot-induced pulmonary embolism. Am. Ht. J. (accepted for publication).

15. Todd, M.H., Cragg, D.J. \& Forrest, J.B. Effects of aspirin on vascular responses to pulmonary embolism. Bibliotheca Anatomica /8 (1979).

16. Gilbert, R.P., Hinshaw, L.B., Kuida, H. \& VISSCHER, M.B. Effects of histamine, 5-hydroxytryptamine and epinephrine on pulmonary hemodynamics with particular reference to arterial and venous segment resistances. Am. J. Physiol. 194: 165-170 (1958).

17. Gurewich, V., Cohen, M.D. \& Thomas, D.P. Humoral factors in massive pulmonary embolism: an experimental study. Am. Heart J. 76: 784-794 (1968).

18. Thomas, D., Stein, M., Tanabe, G., Rege, R. \& WESSLER, $S$. Mechanisms ob bronchoconstriction produced by thromboemboli in dogs. Am. J. Physiol. 206: 1207-1212 (1964).

19. Daily, P.O., Griffin, A., Blackstone, E. \& MOULDER, P.V. The hemodynamic effects of localized pulmonary embolism. Surg. Gynecol. Obstet. I24: 765-773 (1966).

20. Hyman, A.L., Myers, W.D. \& Meyer, A. The effect of acute pulmonary embolus upon cardiopulmonary hemodynamics. Am. Heart J. 67: 313323 (1964).

21. Halmagyi, D.F.J., Starzecki, B. \& Horner, G.J. Humoral transmission of cardiorespiratory changes in experimental lung embolism. Circ. Res. 14: 546-554 (1964).

22. DunN, J.S. The effects of multiple embolism of pulmonary arterioles. Quart. J. Med. 13: 129-147 (1920).

23. Tenney, S.M. \& Miller, R.M. The respiratory 
and circulatory actions of salicylate. Am. J. Med. 19: 498-508 (1955).

24. Walton, R.P. \& Darby, T.D. Circulatory effects of salicylates. Circ. Res. 6: 155-158 (1958).

25. Severinghaus, J.W., Swenson, E.W., Finley, T.N., LATEGOLA, M.T.\& Williams, J. Unilateral hypoventilation produced by occlusion of one pulmonary artery. J. Appl. Physiol. 16:53 (1961).

26. LindSEY, O.O. \& WYLLIE, J.H. Release of prosta- glandins from embolized lungs. Brit. J. Surg. 57: 738-741 (1970).

27. Roth, G., Standfield, N. \& Majerus, P.W. Acetylation of prostaglandin synthetase by aspirin. Proc. Nat. Acad. Sci. USA 72: 3073 (1975).

28. Jose, P., Niederhauser, V., Piper, P.J., RobinSON, C. \& SMITH, A.P. Degradation of prostaglandin $F_{2 \alpha}$ in the human pulmonary circulation. Thorax 31: 713-719(1976).

\section{RÉSUMÉ}

Le pré-traitement à l'aspirine $250 \mathrm{mg} \cdot \mathrm{kg}^{-1}$ et au méthysergide $3 \mathrm{mg} \cdot \mathrm{kg}^{-1}$ ou à une combinaison des deux a été administré au lapin anesthésié avant embolisation pulmonaire provoquée par l'injection d'un caillot de sang autologue de $1.0 \mathrm{ml}$ et comparé à un groupe sans pré-traitement. L'expérience fut continuée jusqu'à ce que chacun des groupes atteigne le nombre de 10 survivants. La mortalité du groupe contrôle a été de 55 pour cent (morts en moins de 30 minutes) comparé à aucun chez les groupes de lapins traités à l'aspirine et à la combinaison aspirine-méthysergide et à 9 pour cent à la méthysergide seule. La pression artérielle est tombée à 60 pour cent de sa valeur pré-embolique deux minutes après embolisation dans le groupe contrôle mais s'est rétablie à 85 pour cent des valeurs pré-emboliques après 60 minutes. Par contre dans le groupe pré-traité à l'aspirine la baisse a été de 82 pour cent à la deuxième minute et 83 pour cent après 60 minutes. de 70 pour cent à deux minutes et 90 pour cent à 60 minutes dans le groupe méthysergide, et une très petite chute de pression à 92 pour cent à deux minutes qui est demeurée inchangée à 60 ième minute dans le groupe où la combinaison avait été employée. La pression ventriculaire droite augmenta de 75 pour cent après deux minutes si on compare aux valeurs pré-emboliques dans le groupe non traité mais était toujours élevée de 37 pour cent après 60 minutes. En comparaison des augmentations à deux et 60 minutes respectivement de 58 pour cent et 23 pour cent dans le groupe aspirine, 65 pour cent et 35 pour cent dans le groupe méthysergide et 55 pour cent et 18 pour cent dans le group combinaison aspirine-méthysergide. La fréquence cardiaque n'a pas changée de façon significative dans aucun des groupes après embolisation.

Ces résultats nous montrent une réduction dramatique du taux de mortalité par embolie pulmonaire lorsque les sujets sont traités à l'aspirine ou au méthysergide, réduction dramatique associée avec une atténuation significative de la réponse hypotensive que l'on trouve chez les lapins contrôle. Ces agents peuvent agir par inhibition de libération des prostaglandines et de la sérotonine. Les effets additifs: de la combinaison aspirinemethysergide employée porte à croire que les deux médiateurs peuvent jouer un rôle dans la réponse hémodynamique causée par l'embolie pulmonaire. 